\title{
FGF23 neutralization improves chronic kidney disease-associated hyperparathyroidism yet increases mortality
}

\author{
Victoria Shalhoub, ${ }^{1}$ Edward M. Shatzen, ${ }^{1}$ Sabrina C. Ward, ${ }^{1}$ James Davis, ${ }^{1}$ Jennitte Stevens, ${ }^{2}$ \\ Vivian $\mathrm{Bi},{ }^{2}$ Lisa Renshaw, ${ }^{2}$ Nessa Hawkins, ${ }^{2}$ Wei Wang, ${ }^{2}$ Ching Chen, ${ }^{2}$ Mei-Mei Tsai, ${ }^{2}$ \\ Russell C. Cattley, ${ }^{3}$ Thomas J. Wronski, ${ }^{4}$ Xuechen Xia, ${ }^{4}$ Xiaodong Li, ${ }^{1}$ \\ Charles Henley, ${ }^{1}$ Michael Eschenberg, ${ }^{5}$ and William G. Richards ${ }^{1}$
}

\begin{abstract}
1Department of Metabolic Disorders, ${ }^{2}$ Department of Protein Sciences, ${ }^{3}$ Department of Pathology, Amgen Inc., Thousand Oaks, California, USA.

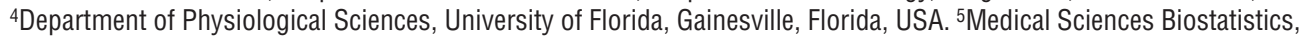
Amgen Inc., Thousand Oaks, California, USA.

\begin{abstract}
Chronic kidney disease-mineral and bone disorder (CKD-MBD) is associated with secondary hyperparathyroidism (HPT) and serum elevations in the phosphaturic hormone FGF23, which may be maladaptive and lead to increased morbidity and mortality. To determine the role of FGF23 in the pathogenesis of CKD-MBD and development of secondary HPT, we developed a monoclonal FGF23 antibody to evaluate the impact of chronic FGF23 neutralization on CKD-MBD, secondary HPT, and associated comorbidities in a rat model of CKDMBD. CKD-MBD rats fed a high-phosphate diet were treated with low or high doses of FGF23-Ab or an isotype control antibody. Neutralization of FGF23 led to sustained reductions in secondary HPT, including decreased parathyroid hormone, increased vitamin $\mathrm{D}$, increased serum calcium, and normalization of bone markers such as cancellous bone volume, trabecular number, osteoblast surface, osteoid surface, and bone-formation rate. In addition, we observed dose-dependent increases in serum phosphate and aortic calcification associated with increased risk of mortality in CKD-MBD rats treated with FGF23-Ab. Thus, mineral disturbances caused by neutralization of FGF23 limited the efficacy of FGF23-Ab and likely contributed to the increased mortality observed in this CKD-MBD rat model.
\end{abstract}

\section{Introduction}

Chronic kidney disease-mineral and bone disorder (CKD-MBD) is a growing health care concern associated with secondary hyperparathyroidism (HPT), mineral abnormalities, increased risk of cardiovascular disease, and elevations in FGF23. FGF23, a hormone secreted primarily by osteoblasts and osteocytes $(1,2)$, is a physiological regulator of circulating phosphate and vitamin D (3). FGF23 was identified as the causative factor of rare hypophosphatemic syndromes characterized by phosphate wasting, low 1,25 dihydroxyvitamin D3 (vitamin D, 1,25[OH $]_{2} \mathrm{D}_{3}$ ) serum levels and rickets or osteomalacia (4-7). In humans, loss of FGF23 function was found to lead to hyperphosphatemia, increased serum vitamin D levels, and ectopic soft-tissue calcifications $(8,9)$. FGF23 target organs comprise those that express coreceptor klotho, such as kidney and parathyroid glands (10). FGF23 functions as a phosphaturic agent by downregulating sodium phosphate cotransporters in the kidney proximal tubule and by inhibiting synthesis of serum vitamin $\mathrm{D}$ through suppression of renal 25-dihydroxyvitamin $\mathrm{D}_{3}$ $1 \alpha$ hydroxylase ( $1 \alpha-[\mathrm{OH}]$ ase) expression (11). In healthy individuals, increased dietary phosphate load has been reported to increase serum levels of FGF23 (12).

In $\mathrm{CKD}$, decreased phosphate excretion due to impaired renal function is accompanied by increases in serum levels of FGF23,

Conflict of interest: This study was funded by Amgen Inc. Victoria Shalhoub, Edward M. Shatzen, Sabrina C. Ward, James Davis, Jennitte Stevens, Vivian Bi, Lisa Renshaw, Nessa Hawkins, Wei Wang, Ching Chen, Mei-Mei Tsai, Russell C. Cattley, Xiaodong Li, Charles Henley, Michael Eschenberg, and William G. Richards are or have been employed by Amgen Inc.

Citation for this article: J Clin Invest. 2012;122(7):2543-2553. doi:10.1172/JCI61405 which maintains normal serum phosphate levels by inducing phosphate excretion and suppressing vitamin D synthesis. This compensatory mechanism fails as kidney failure advances, leading to overt hyperphosphatemia, which, along with lower serum vitamin D levels and hypocalcemia, drives the development of secondary HPT. Growing evidence suggests that serum FGF23 levels are early contributors to the development of secondary HPT through suppression of serum vitamin D and calcium levels $(13,14)$.

CKD patients are at increased risk of cardiovascular disease, the leading cause of mortality in this population (15). Vascular calcification is a prognostic marker of cardiovascular mortality associated with arterial stiffness (16), LV hypertrophy (LVH) (17), and cardiovascular events (18). In addition to "classic" risk factors (i.e., diabetes, hypertension, dyslipidemia, and aging), cardiovascular disease and mortality are associated with "nontraditional" risk factors specific to CKD, such as mineral disturbances (hypercalcemia, ref. 19; and hyperphosphatemia, ref. 20), hormonal imbalances, (e.g., secondary HPT, ref. 21), and elevated serum FGF23 levels. Several studies have reported strong positive associations between serum FGF23 levels and progression to kidney failure (22), LVH (23), cardiovascular events (24), and mortality in patients $(25,26)$ with CKD (predialysis and dialysis) independent of serum phosphate levels. A recent study performed in a large racially diverse nondialysis $\mathrm{CKD}$ population confirmed the association of elevated serum FGF23 levels with LVH (27).

Whether elevated serum FGF23 levels are a direct contributor to cardiovascular disease and mortality or an early biomarker reflecting mineral disturbances in this patient population is an area of considerable interest. FGF23 lacks the typical heparin-binding 

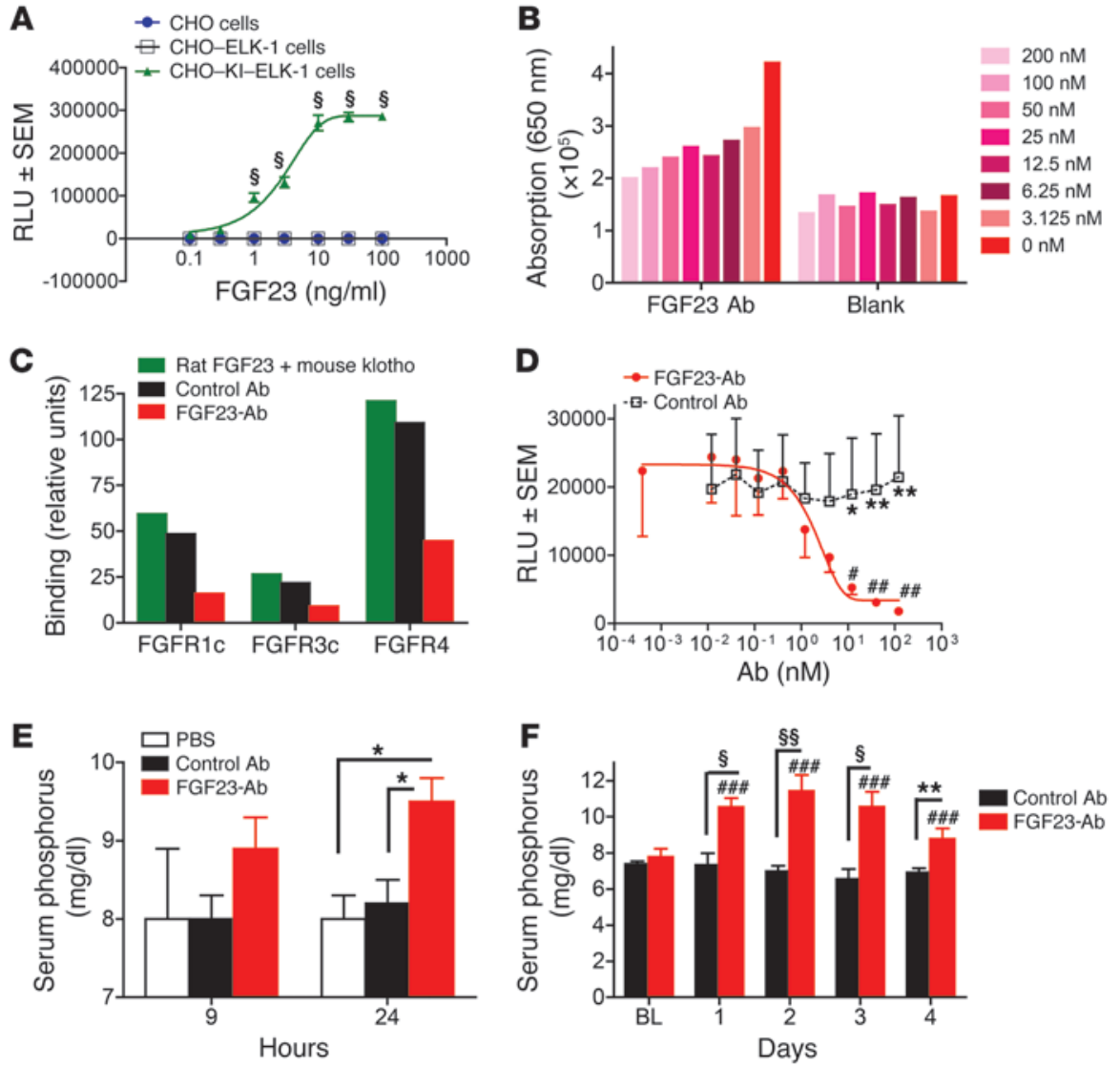

\section{Figure 1}
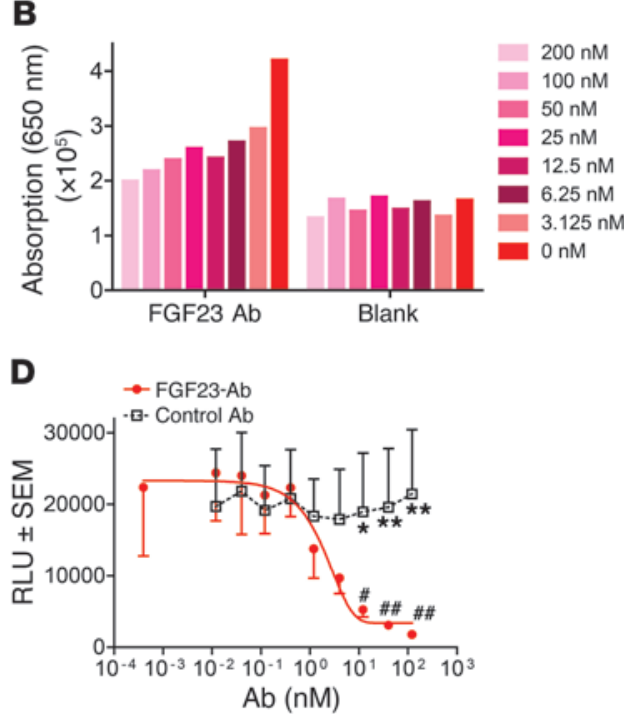

Characterization of FGF23-Abs in normal rodents. (A) Rat FGF23 dose-response in CHO-KI-ELK-1 luciferase reporter cells. $\$ P<0.001$ versus $C H O-E L K-1$ and parental $\mathrm{CHO}$ cells and FGF23, ANOVA plus Tukey's post test. (B) Rat anti-rat FGF23 hybridomaconditioned medium inhibited FGF23 binding to FGFR-KI. Each bar represents the mean result from duplicate wells. Blank, no FGF23 control. (C) FGF23-Ab inhibited binding to FGFRs 1c, 3c, and 4. (D) FGF23$A b$ inhibited FGF23 ELK-1 signaling in CHO-KI cells. ${ }^{*} P<0.05,{ }^{*} P<0.01$ versus FGF23-Ab; $P<0.05$, \#\# $P<0.01$ versus FGF23-Ab, $t$ test. (E) A single FGF23-Ab injection increased serum phosphate in normal mice. Balb/c male mice were injected with FGF23-Ab, control Ab or PBS vehicle ( $n=3$ PBS, $n=7$ control Ab, $n=10$ FGF23Ab; mean $\pm \mathrm{SEM}$; ${ }^{*} P<0.05$ versus PBS or control Ab, ANOVA plus Tukey's post-test). (F) A single FGF23-Ab injection increased serum phosphate in normal rats. Serum phosphate was measured daily for 4 days. ( $n=4$ /group; mean $\pm \mathrm{SEM}$; ${ }^{* *} P<0.01$, $\S P<0.001, \S \S P<0.0001$ versus respective day control $\mathrm{Ab}$, unpaired $t$ test. $\# \# P<0.001$ versus baseline, ANOVA plus Dunnett's multiple comparison test). BL, baseline (time 0) before each treatment was administered. domain found in prototypical FGFs, such as FGF2, necessitating interaction with klotho for high-affinity FGF receptor binding. Studies have suggested that particular heparins may substitute for klotho in the binding of supraphysiological levels of FGF23, leading to FGF2-like receptor activation (28). This observation is of particular interest for the heart because FGF2 is known to cause myocardial hypertrophy in rats $(29,30)$. Consistent with this notion, supraphysiological levels of FGF23 directly induced hypertrophy and the cardiac fetal hypertrophic gene program in isolated ventricular myocytes via FGF receptor activation, notably in the absence of klotho (27). Importantly, intraventricular or intravenous injection of FGF23 in normal mice caused LVH, and in the 5/6Nx CKD rat model, FGF receptor inhibitor treatment improved LVH, supporting a direct maladaptive role for supraphysiological levels of FGF23 on the myocardium (27). Taken together, these findings suggest that while elevated serum FGF23 functions as a phosphaturic hormone to maintain serum phosphate levels in patients with CKD-MBD, the supraphysiological levels may also be maladaptive and contribute to increased secondary HPT, morbidity, and mortality in this population. To address these questions, we generated an FGF23-neutralizing Ab to evaluate whether 6-week chronic administration of FGF23-Ab affected progression of CKD-MBD by altering secondary HPT and associated comorbidities in a rat model of early CKD-MBD.

\section{Results}

FGF23-Ab production and characterization. To mitigate concerns of an immune response, we generated a rat anti-rat FGF23 monoclonal Ab that blocked the ability of FGF23 to bind and signal though its receptors. A stable form of rat FGF23 R176Q/R179Q (FGF23) that dose-dependently increased luciferase reporter activity in CHO cells expressing ELK-1 luciferase reporter (CHO-ELK-1 reporter cells) (half-maximal effective concentration $\left(\mathrm{EC}_{50}\right), 2.8$ $\mathrm{ng} / \mathrm{ml}$ ) (Figure 1A) was used to characterize FGF23-neutralizing Abs. Anti-rat FGF23-Ab-expressing hybridomas generated from rats immunized with wild-type rat FGF23 were screened and found to inhibit FGF23 binding to $\mathrm{CHO}-$ klotho (CHO-Kl) cells. Clone \#58-5 was selected for further characterization based on its binding and inhibitory parameters and is herein referred to as FGF23-Ab. FGF23-Ab dose dependently inhibited FGF23 binding to $\mathrm{CHO}-\mathrm{Kl}$ cells (Figure 1B). Purified FGF23-Ab bound to rat FGF23 with an equilibrium dissociation constant $\left(\mathrm{K}_{\mathrm{D}}\right)$ of less than $2 \mathrm{nM}$, inhibited rat FGF23 plus klotho from binding to immobilized FGFRs (Figure 1C), and blocked FGF23 signaling in CHOELK-1 cells ( $\mathrm{IC}_{50} 2 \mathrm{nM}$ ) (Figure 1D).

FGF23-Ab increased serum phosphate in normal mice and rats. A single injection of FGF23-Ab $(1.25 \mathrm{mg} / \mathrm{kg})$ in mice significantly elevated serum phosphate by 24 hours compared with PBS buffer and rat isotype $\operatorname{IgG} 2 \mathrm{a}$ control $\mathrm{Ab}(P<0.05$ for each; Figure $1 \mathrm{E})$. Similarly, a single injection of FGF23-Ab $(10 \mathrm{mg} / \mathrm{kg})$ in rats significantly elevated serum phosphate by day 1 compared with control $\mathrm{Ab}$ $(P<0.001)$. The serum phosphate remained significantly elevated at day $2(P<0.0001)$, day $3(P<0.001)$, and day $4(P<0.01)$, suggesting inhibition of FGF23's phosphaturic function (Figure 1F), as demonstrated by others (31).

Increased mortality in high-dose FGF23-Ab-treated CKD rats. At different times during the 6 weeks of treatment, some animals died or were found moribund and euthanized (ME). Overall, fewer $5 / 6 \mathrm{Nx}$ 
- Normal + control Ab, ND

- Sham + control Ab, HPD

- 5 5/6Nx + control Ab, HPD

-5/6Nx + FGF23-Ab, $3 \mathrm{mg} / \mathrm{kg}$, HPD

- $5 / 6 \mathrm{Nx}+$ FGF23-Ab, $10 \mathrm{mg} / \mathrm{kg}$, HPD

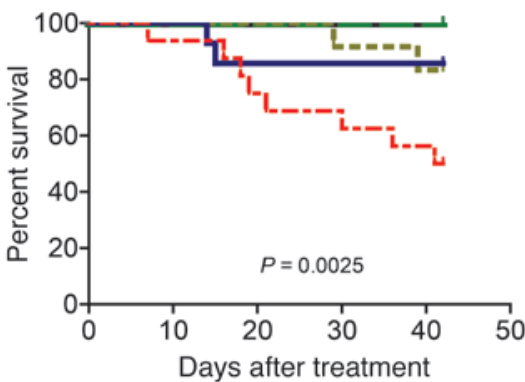

rats survived to the end of the study in the high-dose FGF23-Ab $(10 \mathrm{mg} / \mathrm{kg})$ group (8 survivors out of 16$)$ compared with $5 / 6 \mathrm{Nx}$ control Ab and low-dose FGF23-Ab (3 mg/kg) groups (14 survivors out of 16 in each group). Analysis of the survival curves across all treatment groups demonstrated that the differences were statistically significant ( $P=0.0025$, Figure 2$)$. All ME animals (across $5 / 6 \mathrm{Nx}$ groups) had spikes in blood urea nitrogen (BUN) and serum creatinine levels, comparing the final and penultimate measurements, that were increased more than 2 -fold over baseline values (range 104 to $387 \mathrm{mg} / \mathrm{dl}$ and 1.7 to $5.4 \mathrm{mg} / \mathrm{dl}$, respectively). On average, the decrease in estimated glomerular filtration rate (eGFR) between the baseline assessment and last measurement was greater in rats that did not complete the study than in those that did, and at their last assessment, these rats had a lower eGFR. No animals died in the normal and sham-treated control groups.

\section{Figure 2}

Survival plot demonstrates higher mortality in the high-dose FGF23Ab group. Started with normal + control Ab, ND $(n=10)$; sham-treated + control Ab, HPD $(n=12) ; 5 / 6 \mathrm{Nx}+$ control Ab, HPD $(n=16) ; 5 / 6 \mathrm{Nx}$ + FGF23-Ab (3 mg/kg), HPD ( $n=16) ; 5 / 6 \mathrm{Nx}+$ FGF23-Ab (10 mg/kg), HPD $(n=16)$. Note that the normal + control Ab, ND and the shamtreated + control Ab group results are superimposable at $100 \%$ survival throughout the 6-week treatment period.

Results for animals that died were excluded from further analysis. Data for serum chemistries in the high-dose group (Figures 3 and 4) were obtained from 9 rats, and histopathology data (Tables 1, 2, and 3 ) were obtained from 8 of these 9 rats due to lack of tissue collection from 1 rat that was sacrificed 1 day before the end of the study.

FGF23-Ab treatment altered serum mineral homeostasis and hormones but did not have a major effect on renal function in CKD-MBD 5/6Nx rats. Renal impairment and secondary HPT were apparent at baseline when treatment was initiated 6 weeks after $5 / 6 \mathrm{Nx}$ surgery, which included 3 weeks on a high-phosphate diet (HPD) (Table 4 and Figures 3 and 4). In the $5 / 6 \mathrm{Nx}$ rats, eGFR remained constant throughout the treatment period (Figure $3 \mathrm{~A}$ ) and BUN trended to increase toward the end of the study (Figure 3B). Changes in serum markers, including FGF23 (Figure 3C), consistent with progressive secondary HPT and altered mineral homeostasis (Figure 3, $\mathrm{C}$ and $\mathrm{D}$, and $4, \mathrm{~A}-\mathrm{E}$ ), were observed in nontreated $5 / 6 \mathrm{Nx}$ rats.

FGF23-Ab treatment had no effect on body weight (Table 4), eGFR (Figure 3A), or serum creatinine (data not shown). BUN was significantly higher in the high-dose group than in the $5 / 6 \mathrm{Nx}$ control Ab group at weeks 1,2 , and 4 (Figure 3B). FGF23 neutralization attenuated the $5 / 6 \mathrm{Nx}$-induced increase in serum parathyroid hormone (PTH), with significantly lower mean serum PTH levels in the high-dose group at weeks 1,3 , and 5 and in the

\section{Figure 3}

Effect of FGF23-Ab on renal function, serum FGF23, and PTH levels. (A) GFR was estimated using the formula $\left[\left(U_{c r} \times 24-h \mathrm{vol}\right) / S_{c r}\right.$, where $U_{c r}=$ urinary creatinine, $S_{c r}=$ serum creatinine, and 24- $h \mathrm{vol}=24$-hour urinary volume]. (B) Serum BUN levels. (C) Serum FGF23 levels. FGF23 levels were undetectable in treated rat serum, likely due to a common epitope for FGF23-Ab and an $A b$ in the ELISA. (D) Serum PTH levels. ${ }^{\star} P<0.05,{ }^{* \star} P<0.01,{ }^{\S} P<0.001, \S \S P<0.0001$ for $5 / 6 \mathrm{Nx}+$ control $\mathrm{Ab}$ versus sham-treated + control $\mathrm{Ab} ;{ }^{*} P<0.05,{ }^{\#} P<0.01,{ }^{\ddagger} P \leq 0.0001$ for $5 / 6 \mathrm{Nx}$ + FGF23-Ab (10 mg/kg or $3 \mathrm{mg} / \mathrm{kg}$ ) versus $5 / 6 \mathrm{Nx}$ + control $\mathrm{Ab} ;{ }^{+\dagger} P<0.0001$ for $5 / 6 \mathrm{Nx}$ groups versus sham-treated group at baseline. Data points represent mean \pm SEM derived from the following experimental groups: normal + control Ab, ND $(n=10)$; sham-treated + control Ab, HPD $(n=12) ; 5 / 6 \mathrm{Nx}+$ control Ab, HPD $(n=14) ; 5 / 6 \mathrm{Nx}$ + FGF23-Ab (3 mg/kg), HPD ( $n=14) ; 5 / 6 \mathrm{Nx}+$ FGF23-Ab (10 mg/kg), HPD $(n=9)$.
A

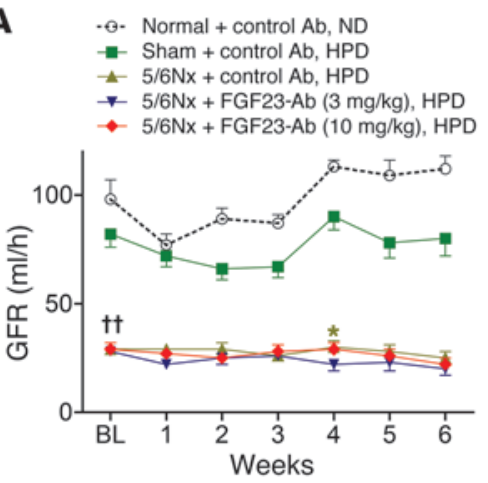

C

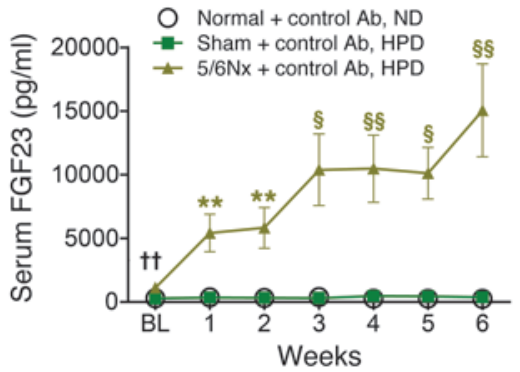

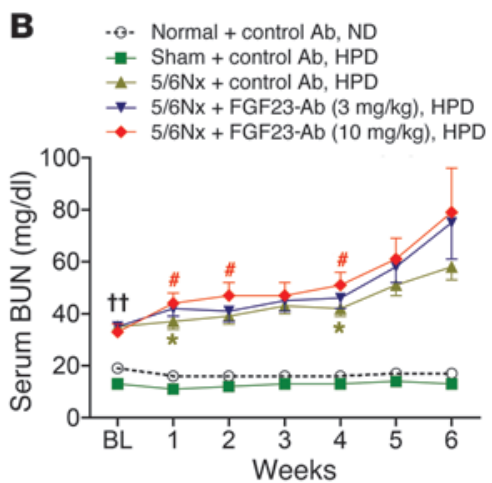

D $\quad$ - - Normal + control Ab, ND - Sham + control Ab, HPD - $5 / 6 \mathrm{Nx}+$ control Ab, HPD $\rightarrow 5 / 6 \mathrm{Nx}+$ FGF23-Ab $(3 \mathrm{mg} / \mathrm{kg}), \mathrm{HPD}$

$\bullet 5 / 6 \mathrm{Nx}+$ FGF23-Ab $(10 \mathrm{mg} / \mathrm{kg}), \mathrm{HPD}$

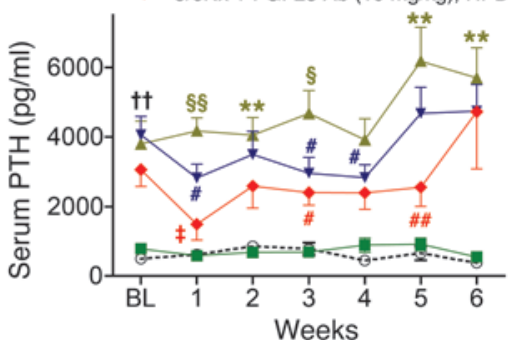


A

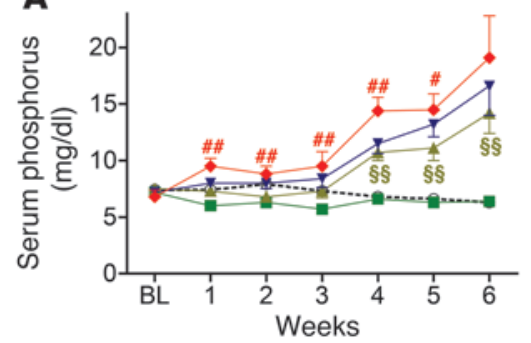

C

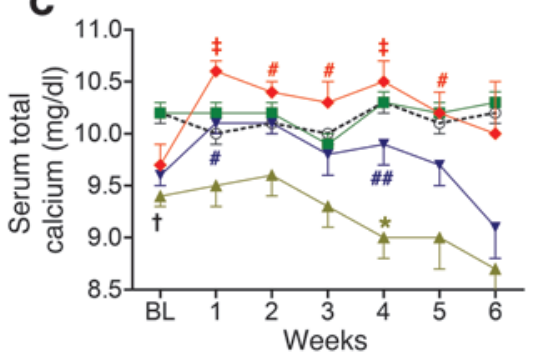

B

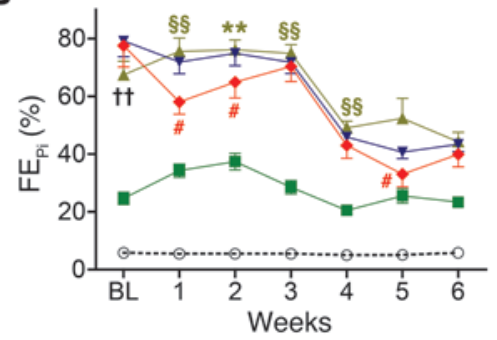

D

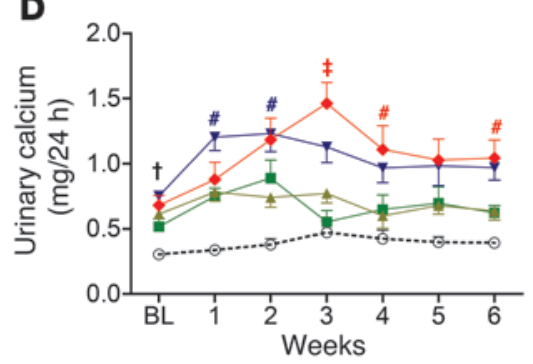

\section{Figure 4}

Treatment of 5/6 nephrectomized rats with FGF23$A b$ increased serum phosphate, calcium, and $1,25(\mathrm{OH})_{2} \mathrm{D}_{3}$ levels. (A) Serum phosphate levels. (B) Fractional excretion of phosphate, $\mathrm{FE}_{\mathrm{Pi}}$. (C) Serum total calcium levels. (D) Urinary calcium. (E) Serum Vitamin $D\left(1,25[\mathrm{OH}]_{2} \mathrm{D}_{3}\right)$ levels. ${ }^{*} P<0.05,{ }^{* *} P<0.01, \S \S P<0.0001$ for $5 / 6 \mathrm{Nx}+$ control $\mathrm{Ab}$ versus sham-treated plus control $\mathrm{Ab}$; ${ }^{\#} P<0.05,{ }^{\#} P<0.01, \ddagger P<0.0001$ for $5 / 6 \mathrm{Nx}$ plus FGF23-Ab (10 mg/kg or $3 \mathrm{mg} / \mathrm{kg}$ ) versus $5 / 6 \mathrm{Nx}$ + control $\mathrm{Ab} ;{ }^{\dagger} P<0.05$, ${ }^{\dagger+} P<0.0001$ for $5 / 6 \mathrm{Nx}$ groups versus sham-treated group at baseline. For urinary calcium, ${ }^{\dagger} P<0.05$ for $5 / 6 \mathrm{Nx}$ low-dose group versus sham-treated group at baseline. Data points represent mean \pm SEM.

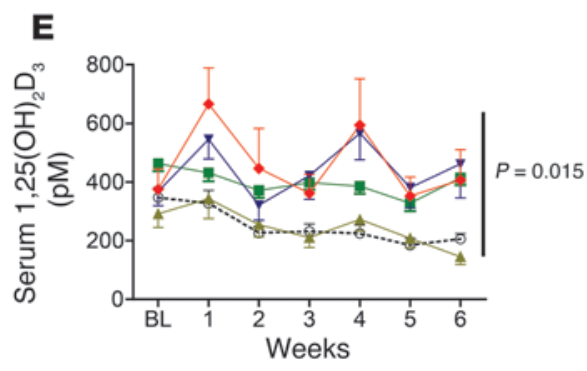

-๑- Normal + control Ab, ND

-- Sham + control Ab, HPD

^ $5 / 6 \mathrm{Nx}+$ control Ab, HPD

$\rightarrow 5 / 6 \mathrm{Nx}+\mathrm{FGF} 23-\mathrm{Ab}(3 \mathrm{mg} / \mathrm{kg}), \mathrm{HPD}$

$\leftarrow 5 / 6 \mathrm{Nx}+$ FGF23-Ab $(10 \mathrm{mg} / \mathrm{kg}), \mathrm{HPD}$

low-dose group at weeks 1,3 , and 4 as compared with the $5 / 6 \mathrm{Nx}$ control Ab group (Figure 3D).

High-dose treatment generally led to significantly higher mean serum phosphate levels than control Ab treatment in $5 / 6 \mathrm{Nx}$ rats (Figure $4 \mathrm{~A})$. Fractional excretion of phosphate $\left(\mathrm{FE}_{\mathrm{P}_{\mathrm{i}}}\right)$ was variable within the high-dose group, but significantly lower at weeks 1, 2, and 5 compared with the $5 / 6 \mathrm{Nx}$ control $\mathrm{Ab}$ group (Figure $4 \mathrm{~B}$ ). The amount of urinary phosphate excretion did not change with FGF23-Ab treatment (data not shown). Mean serum calcium levels in the high-dose group were significantly greater than in the $5 / 6 \mathrm{Nx}$ control $\mathrm{Ab}$ group (Figure $4 \mathrm{C}$ ). The amount of urinary calcium excretion was higher at several time points for both FGF23Ab treatment groups (Figure 4D).

Mean serum vitamin D levels were significantly greater on average across the entire study in the high-dose group compared with the $5 / 6 \mathrm{Nx}$ control Ab group $(P=0.015)$ (Figure 4E), consistent with an upward trend in renal $1 \alpha-(\mathrm{OH})$ ase (Cyp27b1) mRNA observed in FGF23-Ab-treated animals at the end of the study (Figure 5A). Cyp24a1 (25-hydroxyvitamin $\mathrm{D}_{3}$ 24-hydroxylase [24-(OH)ase]) expression, which was significantly elevated by $5 / 6 \mathrm{Nx}$, was not significantly altered by FGF23-Ab administration (Figure 5B). No changes in renal sodium phosphate transporter $(\mathrm{NaP2a}, \mathrm{Slc} 34 \mathrm{a} 1)$ or klotho were observed in animals administered FGF23-Ab compared with $5 / 6 \mathrm{Nx}$ control Ab-treated rats at the end of the study (Figure 5, C and D, respectively). In summary, FGF23-Ab generally reversed CKD-induced secondary HPT and suppression of serum vitamin D and calcium levels (the latter likely triggers for the development of secondary HPT), whereas CKD-induced hyperphosphatemia was exacerbated.
FGF23-Ab treatment did not significantly alter renal pathology in the 5/6Nx model of early CKD-MBD. In contrast to the changes in serum biochemistries, the nephropathy observed in $5 / 6 \mathrm{Nx}$ rats at the end of the study was not affected by FGF23 neutralization as determined by semiquantitative histological examination of remnant kidneys (Table 1 ).

FGF23-Ab treatment did not have an impact on ventricular bypertrophy or hemodynamic parameters. Ventricular hypertrophy, determined as increased gross size of the LV and increased cardiomyocyte diameter, was minimal in both treated and control $5 / 6 \mathrm{Nx}$ animals at the end of the study, with no significant trends in the incidence of ventricular hypertrophy in treated versus nontreated animals (Table 2). Further, FGF23-Ab treatment did not alter 5/6Nx-induced elevations in gene expression of the heart hypertrophy markers, skeletal muscle $\alpha$-actin, heavy chain myosin, and atrial natriuretic peptide (Figure 6, A-D, respectively).

Group mean blood pressures were similar for all animals that had not undergone $5 / 6 \mathrm{Nx}$ (sham-treated and normal control groups) and were consistent with expected hemodynamic parameters from restrained rats. In $5 / 6 \mathrm{Nx}$ rats, no treatment-related changes were observed for mean arterial pressure (MAP), with mean \pm SEM values after 3 weeks of treatment as follows: $123 \pm 14 \mathrm{mmHg}$ for sham, $130 \pm 39 \mathrm{mmHg}$ for $5 / 6 \mathrm{Nx}$ control, $135 \pm 29 \mathrm{mmHg}$ for low dose, and $134 \pm 32 \mathrm{mmHg}$ for high dose. After 6 weeks of treatment, MAP values were $125 \pm 7 \mathrm{mmHg}$ for sham, $145 \pm 32 \mathrm{mmHg}$ for $5 / 6 \mathrm{Nx}$ control, $143 \pm 29 \mathrm{mmHg}$ for low dose, and $134 \pm 32 \mathrm{mmHg}$ for high dose. Although MAP was slightly higher in $5 / 6 \mathrm{Nx}$ groups compared with sham, this was not statistically significant. 
Table 1

Semiquantitative kidney histopathology scores in 5/6Nx and control rats treated with FGF23-Ab or control Ab for 6 weeks

\begin{tabular}{|c|c|c|c|c|c|}
\hline & $\begin{array}{c}\text { Normal + } \\
\text { control Ab (ND) } \\
(n=10)\end{array}$ & $\begin{array}{c}\text { Sham + control } \\
\text { Ab (HPD) } \\
(n=12)\end{array}$ & $\begin{array}{c}5 / 6 \mathrm{Nx}+\text { control } \\
\text { Ab (HPD) } \\
(n=14)\end{array}$ & $\begin{array}{c}5 / 6 \mathrm{Nx}+\mathrm{FGF} 23-\mathrm{Ab} \\
(3 \mathrm{mg} / \mathrm{kg})(\mathrm{HPD}) \\
(n=14)\end{array}$ & $\begin{array}{c}5 / 6 \mathrm{Nx}+\mathrm{FGF} 23-\mathrm{Ab} \\
(10 \mathrm{mg} / \mathrm{kg})(\mathrm{HPD}) \\
(n=8)\end{array}$ \\
\hline \multicolumn{6}{|c|}{ Chronic progressive nephropathy, $n(\%)$} \\
\hline Minimal & $2(20 \%)$ & $2(17 \%)$ & - & - & - \\
\hline \multicolumn{6}{|c|}{ Fibrosis, cortex, focal (CPN), $n(\%)$} \\
\hline Mild & $1(10 \%)$ & $1(8 \%)$ & 0 & 0 & 0 \\
\hline \multicolumn{6}{|c|}{ Basophilia, tubular, cortex (CPN), $n(\%)$} \\
\hline Minimal & $2(20 \%)$ & $1(8 \%)$ & 0 & 0 & 0 \\
\hline Mild & $1(10 \%)$ & $1(8 \%)$ & 0 & 0 & 0 \\
\hline \multicolumn{6}{|c|}{ Infiltration, mononuclear cell, cortex (CPN), $n(\%)$} \\
\hline Minimal & $4(40 \%)$ & 0 & 0 & 0 & 0 \\
\hline \multicolumn{6}{|c|}{ Pyelonephritis (CPN), $n(\%)$} \\
\hline Minimal & 0 & $1(8 \%)$ & 0 & 0 & 0 \\
\hline \multicolumn{6}{|c|}{ Nephropathy, $n(\%)$} \\
\hline Mild & 0 & 0 & $3(21 \%)$ & $3(21 \%)$ & $3(38 \%)$ \\
\hline Moderate & 0 & 0 & $11(79 \%)$ & $10(71 \%)$ & $5(63 \%)$ \\
\hline Marked & 0 & 0 & 0 & $1(7 \%)$ & 0 \\
\hline
\end{tabular}

$n(\%)$, number and percentage of animals per group with pathology severity as indicated; 0 , undetectable. CPN, chronic progressive nephropathy, a background lesion. Semiquantitative scores were obtained by a blinded pathologist. Sham, sham treated.

FGF23-Ab treatment promoted aortic calcification in CKD rats. Aortic calcification was not detected in the $5 / 6 \mathrm{Nx}$ control Ab-treated group. The mean \pm SEM aortic calcification score, as determined by semiquantitative histological assessment ( 0 , none; 1 , minimal; 2 , mild; 3 , moderate; 4 , marked; 5 , severe), was greater in the high-dose than the low-dose group $(3.75 \pm 0.65, n=8$ versus $1.43 \pm 0.36, n=14 ; P=0.0056)$ and significantly higher in both groups than in the $5 / 6 \mathrm{Nx}$ control $\mathrm{Ab}$ group (Figure $7 \mathrm{~A}$; $P<0.0001, P=0.0006$, respectively). "Severe" calcification scores were present only in the high-dose group, in which 7 out of 8 rats had calcified aorta. In the low-dose group, 9 out of 14 rats had calcified aorta. In general, serum phosphate (Figure 4A and Figure 7B) and calcium levels were higher (Figure 4C and Figure 7C) comparing FGF23-Ab groups whose aortae calcified with the $5 / 6 \mathrm{Nx}$ control $\mathrm{Ab}$ group whose aortae did not calcify. Thus, FGF23-Ab treatment was associated with dose-dependent calcification of aortae in $5 / 6 \mathrm{Nx}$ rats.
FGF23-Ab treatment improved bone parameters observed in 5/6 Nx $C K D$ rats. The renal osteodystrophy associated with CKD-MBD and secondary HPT manifested in $5 / 6 \mathrm{Nx}$ control rats as significantly higher cancellous volume, mineralizing surface, mineral apposition rate, and bone formation rate compared with that of sham-treated control rats (Table 3 and Figure 8). Static histomorphometric parameters revealed a significant increase in several parameters (cancellous bone volume, trabecular number, osteoblast surface, osteoid surface, and osteoclast surface) in the $5 / 6 \mathrm{Nx}$ control $\mathrm{Ab}$ group compared with the sham-treated control group. In general, FGF23-Ab treatments decreased these parameters (Table 3). Cancellous bone volume and trabecular number in the high-dose group were not significantly different from those of sham-treated controls (Table 3 and Figure 8, A and D). Although, osteoblast and osteoid surfaces were decreased by high-dose treatment, they remained higher than those of the sham-treated control group. Osteoclast surface was further increased after treat-

Table 2

Semiquantitative heart histopathology scores in 5/6Nx and control rats treated with FGF23-Ab or control Ab for 6 weeks

\begin{tabular}{|c|c|c|c|c|c|}
\hline & $\begin{array}{c}\text { Normal + } \\
\text { control Ab (ND) } \\
(n=10)\end{array}$ & $\begin{array}{c}\text { Sham + control } \\
\text { Ab (HPD) } \\
(n=12)\end{array}$ & $\begin{array}{c}5 / 6 \mathrm{Nx}+\text { control } \\
\mathrm{Ab} \text { (HPD) } \\
(n=14)\end{array}$ & $\begin{array}{c}5 / 6 \mathrm{Nx}+\mathrm{FGF} 23-\mathrm{Ab} \\
(3 \mathrm{mg} / \mathrm{kg})(\mathrm{HPD}) \\
(n=14)\end{array}$ & $\begin{array}{c}5 / 6 \mathrm{Nx}+\text { FGF23-Ab } \\
(10 \mathrm{mg} / \mathrm{kg})(\mathrm{HPD}) \\
(n=8)\end{array}$ \\
\hline \multicolumn{6}{|c|}{ Inflammation, histiocytic, myocardium, $n$ (\%) } \\
\hline $\begin{array}{c}\text { Mild } \\
\text { Hypertrophy, }\end{array}$ & 0 & 0 & $1(7 \%)$ & 0 & 0 \\
\hline $\begin{array}{r}\text { Minimal } \\
\text { Infiltration, } \mathrm{m}\end{array}$ & $\%$ & $3(25 \%)$ & $5(36 \%)$ & $4(29 \%)$ & $4(50 \%)$ \\
\hline Minimal & $3(30 \%)$ & 0 & $2(14 \%)$ & 0 & 0 \\
\hline \multicolumn{6}{|c|}{ Fibrosis, ventricle, myocardium, left, focal/multifocal } \\
\hline Minimal & 0 & 0 & $1(7 \%)$ & 0 & $2(25 \%)$ \\
\hline Mild & 0 & 0 & $2(14 \%)$ & $1(7 \%)$ & $1(13 \%)$ \\
\hline
\end{tabular}

$n$, number of animals per group with pathology as described in column $2 ; 0$, No finding; \%, percentage of animals per group with pathology as described in column 2. Semiquantitative scores were obtained by a blinded pathologist. 
Table 3

Histomorphometry of proximal tibia in 5/6Nx and control rats treated with FGF23-Ab or control Ab for 6 weeks

\begin{tabular}{|c|c|c|c|c|c|}
\hline & $\begin{array}{c}\text { Normal + } \\
\text { control Ab (ND) } \\
(n=10)\end{array}$ & $\begin{array}{c}\text { Sham + control } \\
\text { Ab (HPD) } \\
(n=12)\end{array}$ & $\begin{array}{c}5 / 6 \mathrm{Nx}+\text { control } \\
\text { Ab (HPD) } \\
(n=14)\end{array}$ & $\begin{array}{c}5 / 6 \mathrm{Nx}+\mathrm{FGF} 23-\mathrm{Ab} \\
(3 \mathrm{mg} / \mathrm{kg})(\mathrm{HPD}) \\
(n=14)\end{array}$ & $\begin{array}{c}5 / 6 \mathrm{Nx}+\mathrm{FGF} 23-\mathrm{Ab} \\
(10 \mathrm{mg} / \mathrm{kg})(\mathrm{HPD}) \\
(n=8)\end{array}$ \\
\hline \multicolumn{6}{|l|}{ Dynamic } \\
\hline sLS/BS, \% & $24.63(10.68)$ & $31.17(11.49)$ & $44.55(7.76)^{\mathrm{A}}$ & $44.39(0.89)^{A}$ & $38.75(9.89)$ \\
\hline $\mathrm{dLS} / \mathrm{BS}, \%$ & $18.74(6.58)$ & $9.89(7.10)$ & $13.79(5.23)$ & $14.34(5.12)$ & $7.88(2.97)^{\mathrm{B}}$ \\
\hline $\mathrm{MS} / \mathrm{BS}, \%$ & $31.06(4.34)$ & $25.47(9.36)$ & $36.07(5.88)^{\mathrm{C}}$ & $36.54(6.18)^{C}$ & $27.25(4.91)^{\mathrm{D}}$ \\
\hline $\mathrm{MAR}, \mu \mathrm{m} / \mathrm{d}$ & $1.39(0.30)$ & $1.46(0.24)$ & $2.45(0.51)^{C}$ & $2.72(0.53)^{C}$ & $1.91(0.31)^{\mathrm{B}}$ \\
\hline BFR/BS, $\mu \mathrm{m}^{3} / \mu \mathrm{m}^{2} / \mathrm{d}$ & $0.44(0.15)$ & $0.38(0.17)$ & $0.88(0.22)^{\mathrm{C}}$ & $1.01(0.32)^{c}$ & $0.51(0.08)^{\mathrm{D}}$ \\
\hline \multicolumn{6}{|l|}{ Static } \\
\hline BV/TV, \% & $5.34(3.84)$ & $3.38(2.79)$ & $18.26(14.79)^{A}$ & $10.36(13.34)$ & $2.66(3.75)^{\mathrm{B}}$ \\
\hline Tb.Wi, $\mu \mathrm{m}$ & $25.51(3.44)$ & $27.03(4.75)$ & $32.37(9.83)$ & $25.09(5.53)$ & $23.87(10.28)$ \\
\hline Tb.N, no./mm & $2.37(1.41)$ & $1.44(1.13)$ & $6.98(5.66)^{A}$ & $4.44(5.63)$ & $1.54(1.14)^{\mathrm{B}}$ \\
\hline Tb.Sp, $\mu \mathrm{m}$ & $617.48(542.67)$ & $2225.26(3452.34)$ & 396.30 (764.59) & $2059.74(5841.28)$ & $983.54(619.47)$ \\
\hline Oc.S/BS, \% & $2.7 \pm(1.4)$ & $3.5(1.5)$ & $5.8(2.1)^{\mathrm{E}}$ & $6.3(2.0)^{\mathrm{A}}$ & $9.4(2.6)^{\mathrm{C}, \mathrm{D}}$ \\
\hline Ob.S/BS, \% & $19.7(6.7)$ & $24.7(8.9)$ & $45.8(6.3)^{\mathrm{C}}$ & $42.7(7.0)^{\mathrm{C}}$ & $36.7(6.0)^{\mathrm{A}, \mathrm{D}}$ \\
\hline OS/BS, $\%$ & $17.3(6.3)$ & $21.5(7.9)$ & $41.1(6.5)^{\mathrm{C}}$ & $38.4(7.2)^{\mathrm{C}}$ & $31.5(5.9)^{A, D}$ \\
\hline
\end{tabular}

Data represent mean \pm SD. ${ }^{A} P<0.01$, compared with sham-treated plus control Ab, ANOVA plus Tukey's post-test. ${ }^{B} P<0.05$, compared with $5 / 6 \mathrm{Nx}$ plus control Ab, ANOVA plus Tukey's post-test. ${ }^{C} P<0.001$, compared with sham-treated plus control Ab, ANOVA plus Tukey's post-test. ${ }^{D} P<0.01$ compared with $5 / 6 \mathrm{Nx}$ plus control Ab, ANOVA plus Tukey's post-test. E $P<0.05$, compared with sham-treated plus control Ab, ANOVA plus Tukey's post-test.

ments. Whereas low-dose treatment had no effect on dynamic bone parameters, high-dose treatment returned mean dynamic histomorphometry values to those of the sham-treated control group (Table 3). Thus, FGF23-Ab treatment ameliorated CKDassociated high bone turnover disease.

\section{Discussion}

This study examined the effects of chronic, 6-week FGF23-neutralizing Ab treatment on secondary HPT and comorbidities in a rat CKD model. Many of the mineral disturbances and comorbidities observed in humans with CKD-MBD are also prevalent in this model, including low levels of serum vitamin $\mathrm{D}$ and calcium with increased serum phosphate load and cardiovascular complications, such as LVH. Serum FGF23 levels also rise in 5/6Nx HPD rats, as is observed in humans with CKD (32).

The dosing frequency and FGF23-neutralizing activity of the rat anti-rat FGF23-Ab utilized in this study was determined in vivo by demonstrating a rapid and sustained rise in serum phosphate in normal mice and rats following a single dose of FGF23-Ab. These results were consistent with earlier findings with a different FGF23-Ab (31).
In the current study, FGF23-Ab treatment led to higher serum vitamin $\mathrm{D}$, calcium, and phosphate and lower serum PTH levels for up to 5 weeks compared with those of CKD control rats. Changes in $\mathrm{FE}_{\mathrm{Pi}}$ were variable, and 24-hour urinary phosphate was not affected by FGF23-Ab treatment. Thus, the treatmentinduced worsening of hyperphosphatemia may not be explained solely by lower $\mathrm{FE}_{\mathrm{Pi}}$. The FGF23-Ab-induced elevations in vitamin $\mathrm{D}$, which increases intestinal phosphate uptake, may have partially contributed to hyperphosphatemia in these animals. The serum PTH reductions observed up to week 5 in the high-dose group may have reflected the PTH-lowering effect of increased circulating vitamin D and calcium. Alternatively, FGF23 may have directly regulated PTH expression and secretion by the parathyroid gland (33). Unfortunately, the FGF23-induced suppression of secondary HPT by FGF23-Ab treatment was not sustained in the high-dose group beyond 5 weeks of treatment, when an upward trend in serum PTH levels and an associated serum phosphate load increase were observed in some rats in the high-dose group. Specifically, at week 6, 4 rats had serum PTH levels (range 3870 to 13409 pg/ml) 2-fold higher than

\section{Table 4}

Body and organ weights in 5/6Nx and control rats treated with FGF23-Ab or control Ab for 6 weeks

\begin{tabular}{|c|c|c|c|c|c|c|c|}
\hline & \multicolumn{2}{|c|}{ All rats enrolled in study } & \multicolumn{5}{|c|}{ Rats that completed study } \\
\hline & $n$ & $\begin{array}{l}\text { Pretreatment } \\
\text { BW (g) day } 42\end{array}$ & $n$ & $\begin{array}{l}\text { Pretreatment } \\
\text { BW (g) day } 42\end{array}$ & $\begin{array}{l}\text { Final BW } \\
\text { (g) day } 84\end{array}$ & $\begin{array}{l}\text { Heart weight } \\
\text { (g) day } 84\end{array}$ & $\begin{array}{l}\text { Heart/body weight } \\
\text { ratio (\%) day } 84\end{array}$ \\
\hline Normal + control Ab (ND) & 10 & $408(14)$ & 10 & $408(14)$ & $516(15)$ & $1.53(0.10)$ & $0.30(0.02)$ \\
\hline Sham + control Ab (HPD) & 12 & $427(47)$ & 12 & $427(47)$ & $511(64)$ & $1.46(0.18)$ & $0.29(0.01)$ \\
\hline 5/6Nx + control Ab (HPD) & 16 & $329(40)^{A, B}$ & 14 & $340(38)^{A, B}$ & $382(57)^{A, B}$ & $1.36(0.16)$ & $0.36(0.04)^{B, C}$ \\
\hline $5 / 6 \mathrm{Nx}+\mathrm{FGF} 23-\mathrm{Ab}$ (3 mg/kg) (HPD) & 16 & $336(38)^{A, B}$ & 14 & $339(39)^{A, B}$ & $383(72)^{A, B}$ & $1.46(0.18)$ & $0.39(0.05)^{A, B}$ \\
\hline 5/6Nx + FGF23-Ab (10 mg/kg) (HPD) & 16 & $344(41)^{A, B}$ & 8 & $347(62)^{B, C}$ & $380(62)^{A, B}$ & $1.52(0.23)$ & $0.41(0.07)^{A, B}$ \\
\hline
\end{tabular}



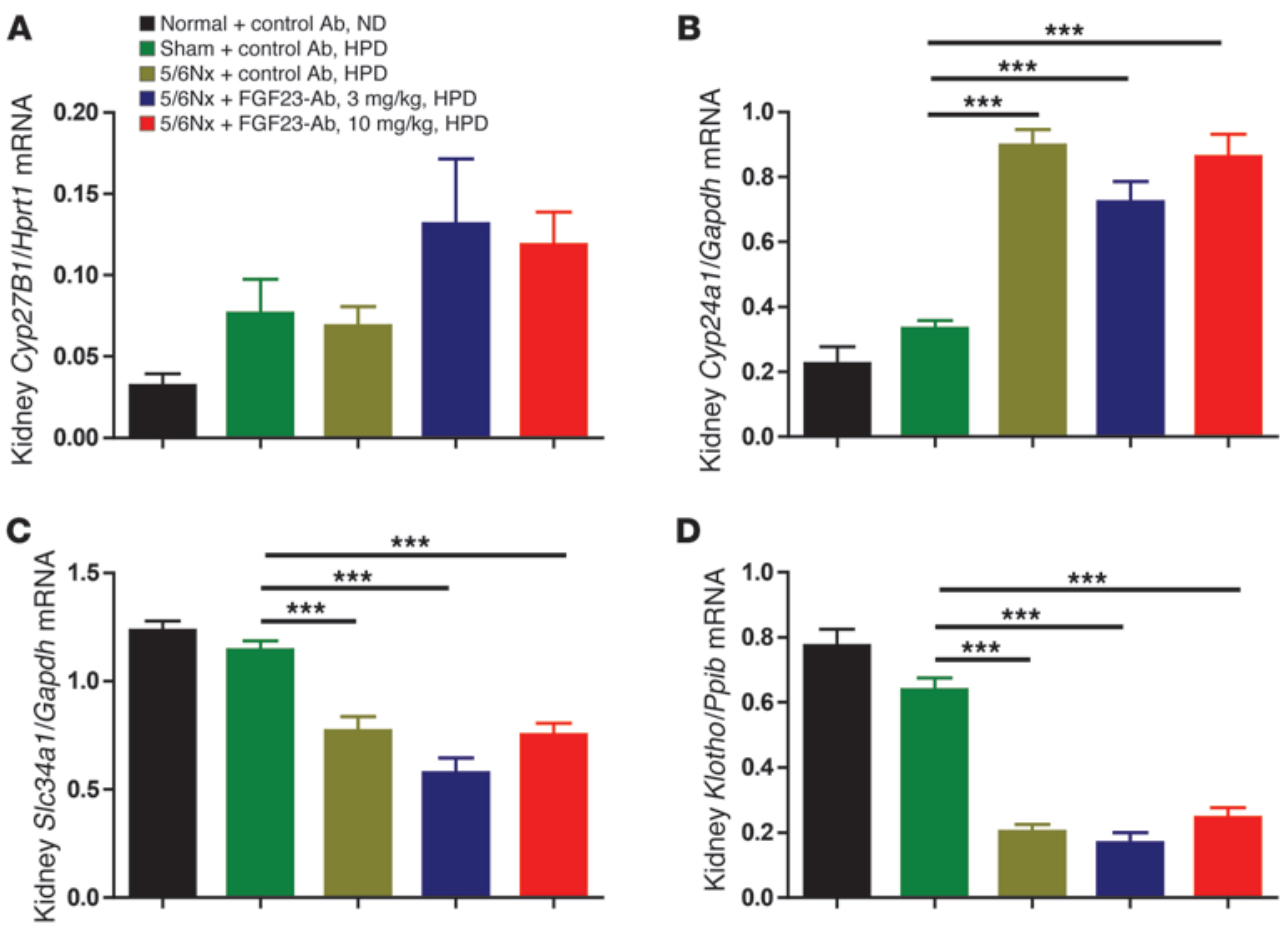

D

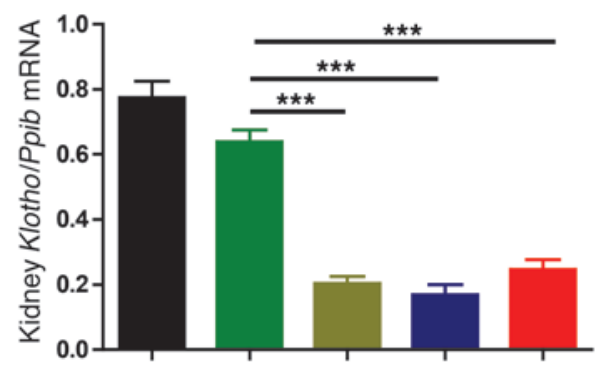

\section{Figure 5}

FGF23-Ab treatment did not significantly affect expression of markers of kidney pathology. (A) Cyp27b1 $(1 \alpha[\mathrm{OH}]$ ase). (B) Cyp24a1 (24[OH]ase). (C) Slc34a1 (NaPi2a). (D) Klotho. Transcript levels were normalized to mRNA levels for Gapdh, Hprt1, Ppib in the same sample. ${ }^{* * *} P<0.001$ for comparisons as designated on figures. Animal numbers in each group are the same as those described in Figure 3, except for 5/6Nx + FGF23-Ab (10 mg/kg), HPD ( $n=8$ instead of 9$)$. Data represent mean \pm SEM. baseline and serum phosphate levels (range 17.3 to $38.0 \mathrm{mg} / \mathrm{dl}$ ) 3- to 4-fold higher than baseline.

Most importantly, more ME rats were found in the high-dose group than in the low-dose and control Ab $5 / 6 \mathrm{Nx}$ groups. The increased mortality in the FGF23-Ab high-dose group was at least partially attributed to renal failure and was not due to Ab load, since the $5 / 6 \mathrm{Nx}$ control $\mathrm{Ab}$ group received an equivalent amount $(10 \mathrm{mg} / \mathrm{kg})$ of control Ab with the same dosing frequency.
CKD rats in this study were fed a HPD, which raises the question of whether certain results, such as the observed increase in vascular calcification in the FGF23-Ab-treated animals, might have been different using a normal- or low-phosphate-containing diet. The HPD was chosen because it simulates the Western diet of many CKD patients (34-37) and potentiates disease progression in the $5 / 6 \mathrm{Nx}$ rats, which facilitates studying this disease model. It is possible that a normal- or low-phosphate diet
$\mathbf{A}$

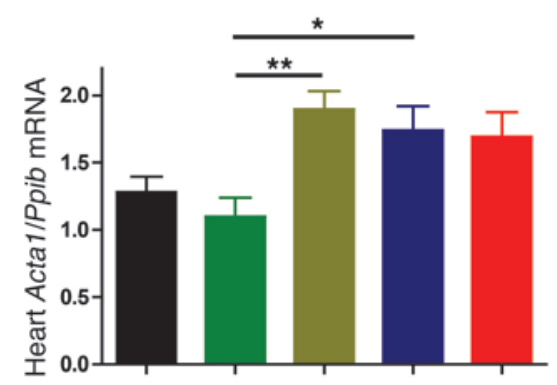

Figure 6

FGF23-Ab treatment had no effect on increased expression of cardiac hypertrophy markers. (A) Acta1. (B) Acta2. (C) Myh7. (D) Nppb. Transcript levels were normalized to mRNA levels for Gapdh, Hprt1, or Ppib in the same sample. ${ }^{*} P<0.05$, ${ }^{\star \star} P<0.01$ for comparisons as designated on figures. Animal numbers in each group are the same as those described in Figure 5. Data represent mean \pm SEM.
C

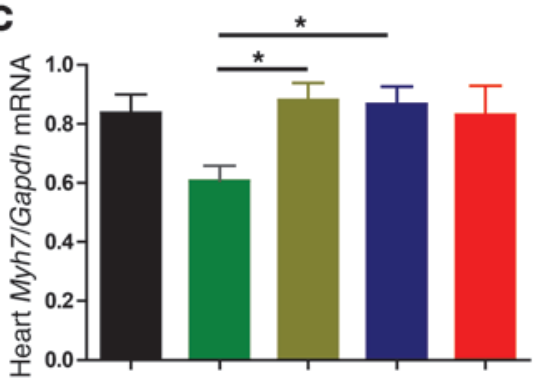

B

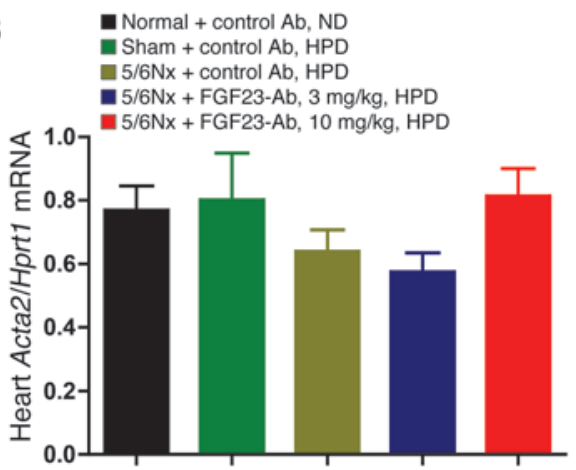

D

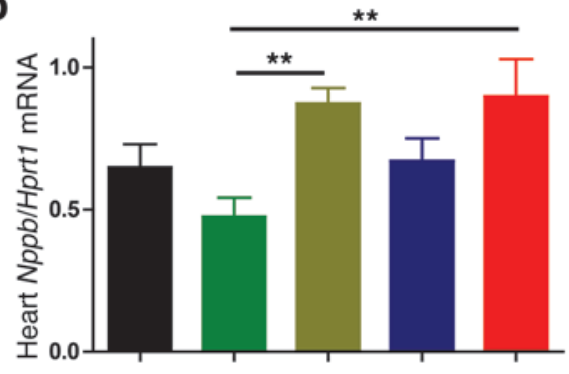



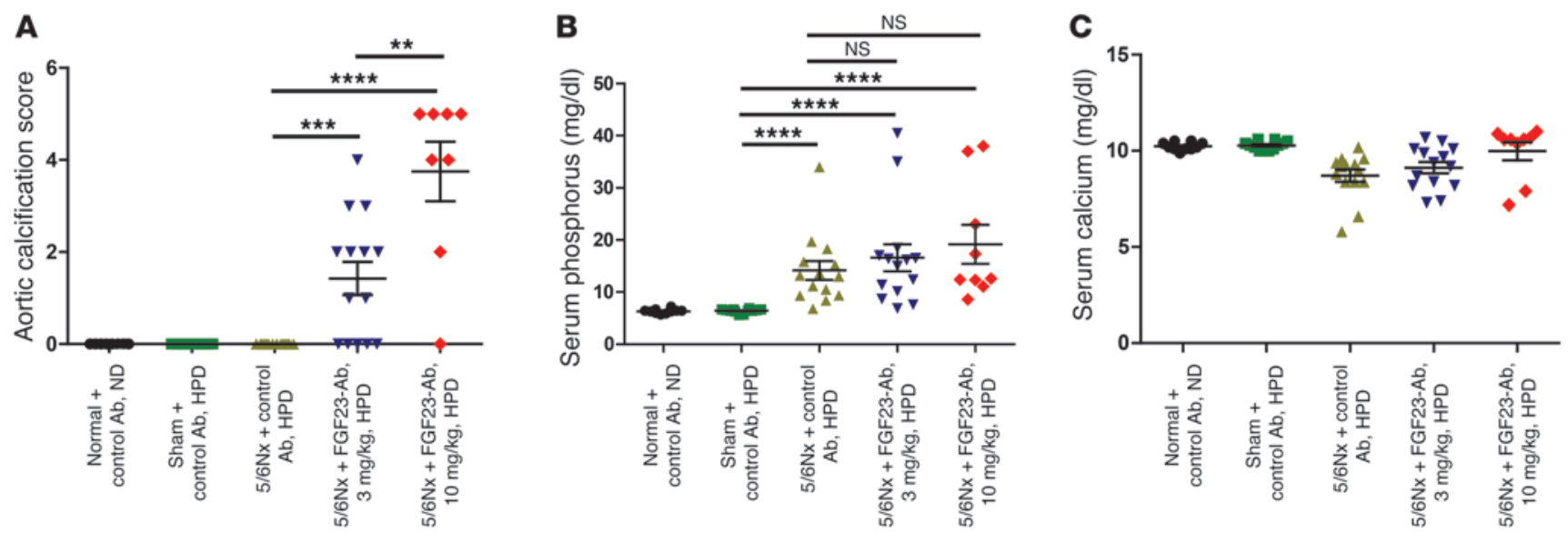

Figure 7

FGF23-Ab increases aortic calcification in 5/6Nx rats on a high-phosphate diet. (A) Aortic calcification score was higher for FGF23-Ab-treated $5 / 6 \mathrm{Nx}$ rats after 6 weeks of treatment. Semiquantitative mean calcification score: none, 0; minimal, 1; mild, 2; moderate, 3; marked, 4 ; severe, 5. Overall comparison for CKD groups: $P<0.0001$ Kruskal-Wallis test. (A) ${ }^{* *} P=0.0056,{ }^{* * *} P=0.0006,{ }^{* * *} P=0.0001$, Wilcoxon's exact test; (B) Serum phosphorus, ${ }^{* * *} P<0.0001$. (C) Serum calcium. No significance between sham-treated and/or $5 / 6 \mathrm{Nx}$ groups. Animal numbers in each group are the same as those described in Figure 5. Results are presented for individual animals and mean \pm SEM.

would lessen the extent of FGF23-Ab-induced mineral imbalances, thus preventing the occurrence of vascular calcifications observed in this study. However, the observed elevation in serum phosphate is a predicted pharmacodynamic outcome of FGF23 neutralization when functional target tissue (i.e., kidney) is present. Indeed, in other studies in normal mice and CKD rats fed a normal-phosphate-containing diet, FGF23-neutralizing Abs also increased serum phosphate, but the long-term effect of FGF23 neutralization on vascular calcification was not examined $(31,38)$. The appearance of soft tissue calcifications is also observed in FGF23-null mice that exhibit deregulated mineral metabolism (3). Future studies using dietary or pharmacological control of phosphate and studies using phosphate and FGF23 clamping are needed to better determine the direct contribution of impaired phosphate and mineral homeostasis to the pronounced vascular calcification and morbidity observed upon FGF23-Ab treatment in this study.

The increased serum calcium caused by FGF23-Ab treatment likely resulted from the higher serum vitamin $\mathrm{D}$, which would lead to increased intestinal calcium absorption. Concordantly, FGF23null mice exhibited elevated serum vitamin $\mathrm{D}$ and calcium despite lower serum PTH (3). The increased urinary calcium observed in FGF23-Ab-treated CKD rats is consistent with higher serum calcium and lower tubular calcium reabsorption in response to reduced serum PTH levels brought about by prolonged suppression of FGF23, higher vitamin D and calcium, and contrasts with findings in FGF23-overexpressing mice (39). The contribution of increased osteoclast activity to higher serum calcium (and phosphate) levels after treatment is unknown, but remains a formal

\section{Figure 8}

Histology of rat proximal tibia showing increased bone/osteoid accumulation in 5/6Nx control animals and improvement upon FGF23-Ab treatment. Bone sections were subjected to von Kossa and tetrachrome staining. (A) Normal plus control Ab; (B) sham-treated plus control $\mathrm{Ab}$; (C) $5 / 6 \mathrm{Nx}$ plus control Ab. (D) $5 / 6 \mathrm{Nx}+$ FGF23-Ab (10 mg/kg). Original magnification, $\times 40$. possibility given the increase in osteoclast surface observed at the end of the study in FGF23-Ab-treated CKD rats.

The lack of an FGF23-Ab effect on renal $1 \alpha-(\mathrm{OH})$ ase and 24-(OH) ase expression likely reflects the opposing actions of elevated circulating PTH and FGF23 at week 6. Additionally, lack of FGF23-Ab's effect on $\mathrm{NaP2}$ a expression is consistent with no observed effect on $\mathrm{FE}_{\mathrm{Pi}}$ at week 6 and likely also due to the higher serum levels of PTH as a negative regulator of $\mathrm{NaP} 2 \mathrm{a}(40,41)$, at this final time point.

The observation in this study that FGF23-Ab treatment deregulated mineral homeostasis and caused vascular calcification coupled with published data from FGF23 loss-of-function mutations in mice that also exhibit elevated serum phosphate and increased soft tissue and vessel calcifications in the presence of a functioning
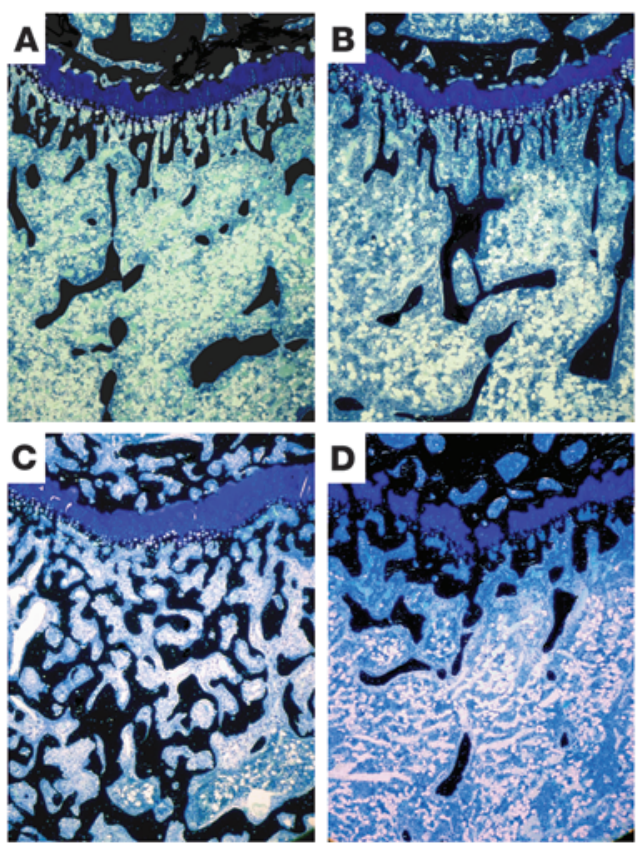
kidney (3) implicate a contribution of increased serum phosphate levels to this pathology. FGF23-Ab-treated rats with aortic calcifications had normal or elevated serum calcium and higher serum phosphate than that found in $5 / 6 \mathrm{Nx}$ control $\mathrm{Ab}$ rats, whose aortae did not calcify. Although unlikely, due to the continued elevations in serum phosphate during the treatment period that indicated FGF23 activity was continuously inhibited, we cannot exclude the possibility that the high-dose FGF23-Ab elicited a compensatory response in FGF23 that may have had a direct impact on the vessel wall. Given data implicating elevated serum phosphate, potentiated by increased serum vitamin $\mathrm{D}$, in promoting vascular calcification $(42,43)$, sustained elevations of high serum phosphate in the presence of elevated vitamin D likely contributed directly to the vascular calcification observed in the high-dose group.

Numerous studies have correlated increased serum FGF23 levels with CKD disease progression, $\mathrm{LVH}$, cardiovascular disease, and mortality (22-26). Recently, local and systemic FGF23 administration to normal mice induced pathological heart remodeling and marker gene expression (27). Together with in vitro studies using cardiomyocytes, these studies indicated that FGF23 can have a direct impact on the heart. In our study, heart/body weights were higher for $5 / 6 \mathrm{Nx}$ rats, and expression of pathological heart hypertrophic markers were elevated, despite minimal LVH. Significant LVH may have required a longer time to manifest and or more detailed quantitative histomorphometric microanalyses. Nonetheless, we detected no treatment effect of FGF23-Ab on the cardiac parameters measured. Our study differed from that by Faul et al. (27), who administered a nonspecific FGF receptor inhibitor to $5 / 6 \mathrm{Nx}$ rats fed a normal diet immediately after $5 / 6 \mathrm{Nx}$ surgery for 14 days, whereas FGF23-Ab was dosed after established renal failure ( 6 weeks after $5 / 6 \mathrm{Nx}$ ) in HPD-fed rats for an additional 6 weeks. As mentioned, our findings are complicated by disturbances in mineral homeostasis that resulted from longer-term FGF23-Ab treatment, whereas no such disturbances were reported by Faul et al. (27).

It is of interest that even in the context of deregulated mineral homeostasis, FGF23-Ab treatment improved the hyperparathyroid bone disease observed in CKD-MBD 5/6Nx rats. The observed improvements in bone parameters were consistent with the degree of serum PTH reduction resulting from FGF23-Ab administration. The described relationship between improved bone mineralization and decreased vascular calcifications (44) was not observed in this model. It is likely that the contrasting effects of FGF23-Ab on bone and the vasculature were, in part, secondary to effects on vitamin $\mathrm{D}$, phosphate, and PTH. Increased serum vitamin D and decreased serum PTH likely contributed to improvements in bone turnover and mineralization observed in this model, whereas elevated serum vitamin $\mathrm{D}$ and concomitant disturbances in mineral balance caused by FGF23 neutralization promoted calcification.

In conclusion, in a rat model of early CKD fed a HPD, chronic neutralization of FGF23 increased serum vitamin $D$, decreased secondary HPT, and improved numerous bone parameters. Unfortunately, these beneficial effects were countered by increased serum phosphate levels, resulting in part from the inhibition of FGF23's phosphaturic activity on the residual kidney, which likely contributed to the increased mortality and vascular calcification observed in rats treated with the high dose of FGF23-Ab. Additional studies are needed to assess the effect of FGF23 neutralization in CKDMBD rats with adequately controlled phosphate levels and at different stages of CKD, including end-stage renal disease. In dialysis patients, FGF23 levels are significantly elevated, and the phospha- turic effect of FGF23 is less relevant because of diminished renal function. Whether neutralizing FGF23 in these individuals would ameliorate the proposed deleterious extrarenal effects of supraphysiological FGF23 on the cardiovascular system (27) while obviating the impairments of mineral homeostasis described in this manuscript warrants further studies in preclinical models.

\section{Methods}

\section{Rat anti-rat FGF23-Ab generation}

Rats were immunized with CHO cell-expressed, wild-type rat FGF23. Hybridoma supernatants were screened for FGF23-specific Abs using an indirect ELISA with immobilized goat anti-rat IgG followed by a Biacore sensor chip-binding assay: anti-FGF23-Abs were captured by goat antimurine-Fc immobilized on Biacore sensor chips, and FGF23 (100 nM) binding to the captured Abs was monitored.

$\mathrm{CHO}-\mathrm{Kl}$-expressing cell binding assay. $\mathrm{CHO}-\mathrm{Kl}$ cells were seeded 6 hours before assay. Abs (in 10\% conditioned medium final concentration) were preincubated with biotinylated rat FGF23 for 1 hour in assay buffer $(2 \%$ BSA in PBS with $\mathrm{Ca}^{+2}$ and $\mathrm{Mg}^{+2}$ ). FGF23-Abs were incubated with $\mathrm{CHO}-\mathrm{Kl}$ cells for 1 hour. Streptavidin-europium was added for an additional 15 minutes before measuring FGF23 binding.

Biacore sensor chip inhibition binding assay. FGFRs 1c, 3c, and 4 were immobilized onto Biacore chips (GE Healthcare), and purified FGF23 (20 nM) $+\mu$ klotho $(20 \mathrm{nM})$ binding was examined after preincubation for $30 \mathrm{~min}$ utes with anti-FGF23-Abs (500 nM).

FGF23 and purified FGF23-neutralizing Ab activity assays. Parental CHO cells, CHO-ELK-1, or CHO-ELK-1 luciferase reporter cells expressing $\alpha$ klotho (CHO-Kl-ELK-1) were serum deprived overnight and exposed for 4 hours to rat FGF23R176Q/R179Q (40 pM), rat FGF23R176/179Q preincubated for 30 minutes with anti FGF23-Abs $\left(10^{-4}\right.$ to $\left.10^{3} \mathrm{nM}\right)$, or control medium. Luciferase reporter activity was assayed. Each FGF23-Ab was then evaluated in normal male Balb $/ \mathrm{c}$ mice ( $1.25 \mathrm{mg} / \mathrm{kg}$, i.v., $n=5$ to 10$)$ and normal young-adult male Sprague Dawley rats $(10 \mathrm{mg} / \mathrm{kg}$, i.p., $n=4)$ for its ability to increase serum phosphate. Polyclonal goat anti-human FGF23-Ab (R\&D Systems), a rat isotype control Ab (IgG2a), and Ab vehicle (PBS) were used as controls.

\section{Animals, surgery, and treatment}

Chronic renal insufficiency was induced by a 2-step surgery in age-matched male Sprague Dawley rats ( 250 to $275 \mathrm{~g}$; 95 days old) by a procedure that reduces the original functional renal mass by five-sixths $(5 / 6 \mathrm{Nx})(45)$. The second surgery occurred 6 weeks prior to treatment. Day 0 of the study is defined as the date of the initiation of compound treatment. After surgery, Harlan-Tekland 22/5 diet 8640 (normal diet; ND) (1.13\% calcium, $0.94 \%$ phosphorus, $22.58 \%$ protein, $2.99 \mathrm{IU}$ vitamin D) was provided to all animals ad libitum. Three weeks prior to treatment, all animals that had undergone sham or $5 / 6 \mathrm{Nx}$ surgery were provided a HPD $(0.6 \% \mathrm{Ca}, 1.21 \% \mathrm{P}, 18.6 \%$ protein, 2.2 IU vitamin D; 585Y, Dyets Inc.) ad libitum, except during fasting for urine collection, until necropsy. Normal control animals continued on ND until scheduled necropsy. Body weights were measured for all animals once weekly ( \pm 1 day) starting 3 weeks prior to treatment. 5/6 Nx groups were balanced based on body weight, serum creatinine and phosphorus, BUN and PTH levels: (a) ND, $n=10$; (b) sham-treated HPD, $n=12$; (c) $5 / 6 \mathrm{Nx}$ + control Ab (HPD), $n=16$; (d) 5/6Nx + FGF23-Ab (3 mg/kg) (HPD), $n=16$; (e) $5 / 6 \mathrm{Nx}+$ FGF23-Ab $(10 \mathrm{mg} / \mathrm{kg})(\mathrm{HPD}), n=16$. Neutralizing FGF23-Ab or an isotype control Ab (IgG2a) was then administered 3 times per week for 6 weeks beginning on day 0 (baseline) via intraperitoneal administration. Animals were dosed at $6 \mathrm{ml} / \mathrm{kg}$. Mortality was tracked throughout the study. Necropsy was not performed on animals that died early. 


\section{Blood and urine collection and chemistry analysis}

Heparinized blood was collected weekly from the jugular veins of isofluorane-anesthetized $5 / 6 \mathrm{Nx}$ animals starting after surgeries and continuing through the end of treatment at week 6 . Blood samples were processed for serum, and the various chemistry parameters were determined using an Olympus AU640e Chemistry-Immuno Analyzer. Serum PTH was assayed using a bioactive, intact PTH (iPTH) ELISA (Immutopics) and serum FGF23 using an intact FGF23 ELISA (Kainos). Animals were placed into metabolic cages once weekly beginning 1 week before treatment and continuing through the end of treatment at week 6 . Urine samples were collected on wet ice for at least 8 hours and not more than 18 hours. Data were adjusted to tabulate per 24-hour collection. The animals were not offered food while housed in the metabolism cage. Urine samples were analyzed for the various parameters shown in Figure 2 using an Olympus AU640e Chemistry Immuno-Analyzer. eGFR was determined using the following formula: (urine creatinine $\times 24$-hour urine volume/serum creatinine).

\section{$1,25(\mathrm{OH})_{2} \mathrm{D}_{3}$ analysis}

Serum (150 $\mu$ l aliquots) was collected into glass tubes with Teflon liner caps and stored at $-70^{\circ} \mathrm{C}$ until analysis. The samples were analyzed in such a manner that a single animal's samples from all time points were analyzed in a single run. The samples were analyzed using an assay from Immunodiagnostic Systems Inc.

\section{Cancellous bone histomorphometry}

Xylenol orange $(90 \mathrm{mg} / \mathrm{kg})$ was administered s.c. on day 74 and calcein (10 $\mathrm{mg} / \mathrm{kg}$ ) on day 81 . At harvest, 1 tibia was immersed in zinc formalin for 24 hours, placed in $70 \%$ ethanol, and processed for plastic embedding. Bone samples (proximal tibiae from rats) were dehydrated in increasing concentrations of ethanol and embedded undecalcified in modified methyl methacrylate. Longitudinal sections of embedded bones were cut at thicknesses of 4 and $8 \mu \mathrm{m}$ with Leica/Jung 2065 and 2165 microtomes. The thinner sections were stained according to the von Kossa method with a tetrachrome counterstain, while the thicker sections remained unstained for collection of fluorochrome-based data. All data were collected with the Osteomeasure System (OsteoMetrics). The sample area (region of interest) within the proximal tibial metaphysis began $0.5 \mathrm{~mm}$ proximal to the growth plate to exclude the primary spongiosa. The following variables were measured in the stained sections: cancellous bone volume (BV/TV, $\%)$, trabecular width ( $\mathrm{Tb} . \mathrm{Wi}, \mu \mathrm{m})$, trabecular number (Tb.N, no. $/ \mathrm{mm}$ ), trabecular separation (Tb.Sp, $\mu \mathrm{m}$ ), osteoclast surface (Oc.S/BS, \%), osteoblast surface (Ob.S/BS, \%), and osteoid surface (OS/BS, \%). The following fluorochrome-based variables were measured in the unstained sections: single-labeled surface (sLS/BS, \%), double-labeled surface, (dLS/BS, \%), mineralizing surface (MS/BS, [dLS + sLS/2]/BS, \%), mineral apposition rate $(\mathrm{MAR}, \mu \mathrm{m} / \mathrm{d})$, and bone formation rate $(\mathrm{BFR} / \mathrm{BS}, \mathrm{MS} / \mathrm{BS} \times \mathrm{MAR}$, $\left.\mu \mathrm{m}^{3} / \mu \mathrm{m}^{2} / \mathrm{d}\right)$. Rats were distributed to the experimental groups as follows: normal + control Ab, ND ( $n=10$; sham-treated + control Ab, $\operatorname{HPD}(n=12)$; $5 / 6 \mathrm{Nx}+$ control Ab, HPD $(n=14) ; 5 / 6 \mathrm{Nx}+$ FGF23-Ab $(3 \mathrm{mg} / \mathrm{kg}), \mathrm{HPD}$ $(n=14) ; 5 / 6 \mathrm{Nx}+\mathrm{FGF} 23-\mathrm{Ab}(10 \mathrm{mg} / \mathrm{kg}), \operatorname{HPD}(n=8)$.

\section{Histopathological assessments of the remnant kidney}

Remnant kidneys were isolated at the end of the study and processed for histology. All sections were reviewed semiquantitatively by a pathologist blinded to the study design. Nephropathy was categorized by the presence of several findings within both the renal cortex and medulla. These findings included interstitial fibrosis; mononuclear to mixed cell tubule interstitial inflammation; tubular changes, which included tubular necrosis, degeneration, regeneration, ectasia, and luminal casts; multifocal mineral- ization; rare arterial vascular changes, including intimal/medial hyperplasia; and secondary glomerular changes, including rare multifocal proliferative glomerulopathy and glomerulitis.

\section{Histopathological assessments of heart and aorta}

Heart weights were obtained at harvest. Hearts and thoracic aortae were processed for histology. von Kossa-stained sections of the aortic arch region were examined semiquantitatively by a blinded pathologist who scored the degree of mineralization using as follows: 0 , none; 1 , minimal; 2 , mild; 3 , moderate; 4 , marked; 5 , severe. The average score was obtained and reported as mean \pm SEM from the following groups of animals: normal + control Ab, ND $(n=10)$; sham-treated + control Ab, $\operatorname{HPD}(n=12)$; $5 / 6 \mathrm{Nx}+$ control Ab, HPD $(n=14) ; 5 / 6 \mathrm{Nx}+$ FGF23-Ab $(3 \mathrm{mg} / \mathrm{kg}), \mathrm{HPD}$ $(n=14) ; 5 / 6 \mathrm{Nx}+\mathrm{FGF} 23-\mathrm{Ab}(10 \mathrm{mg} / \mathrm{kg}), \operatorname{HPD}(n=8)$.

\section{RNA analysis}

RNA homogenates of kidney and heart ventricles were prepared using the QuantiGene Sample Processing Kit for Frozen Animal Tissue (Affymetrix Inc.) from each animal group: normal + control Ab, ND $(n=10)$; sham-treated + control Ab, HPD $(n=12) ; 5 / 6 \mathrm{Nx}+$ control Ab, $\operatorname{HPD}(n=14) ; 5 / 6 \mathrm{Nx}+\mathrm{FGF} 23-\mathrm{Ab}(3 \mathrm{mg} / \mathrm{kg}), \operatorname{HPD}(n=14) ; 5 / 6 \mathrm{Nx}+$ FGF23-Ab $(10 \mathrm{mg} / \mathrm{kg}), \operatorname{HPD}(n=8)$. RNA was assayed using the Kidney Plex Set 31037 (Cyp24a1 [24-(OH)ase], Cyp27b1, Slc34a1 [NaPi2a], klotho); Heart Plex Set 31119 (Natriuretic peptide precursor type B $[N p p b]$, myosin heavy chain 7 , cardiac muscle, $\beta[M y b 7]$, $\alpha 1$-actin skeletal muscle [Acta1], smooth muscle $\alpha$ actin [Acta2]). Housekeeping genes were included in each Plex Set as follows: Gapdh, hypoxanthine guanine phosphoribosyl transferase (Hprt), or peptidylprolyl isomerase B (Ppib, cyclophilin B) (Affymetrix Inc.).

\section{Statistics}

Values for BUN, serum creatinine, serum phosphate, serum PTH, serum total calcium, and serum vitamin D were log transformed prior to statistical analysis. Results from rats prematurely euthanized were excluded from all analyses. Vitamin D values reported as lower limit of quantification (LLQ) were assigned a value of 20 for the statistical analysis (the lower limit of detection for the assay). $P<0.05$ was considered significant. Unless stated otherwise, figures present mean \pm SEM. A survival graph was created using the product limit method of Kaplan-Meier to illustrate the time at which deaths occurred within each treatment group. Survival curves were compared using the log-rank test.

Renal impairment was verified by employing an ANOVA for each parameter at baseline (values obtained prior to treatment administration) with each $5 / 6 \mathrm{Nx}$ group compared with the sham-treated group using Dunnett's post-hoc test.

An ANOVA at each assessment was employed on serum phosphate for studies that did not include $5 / 6 \mathrm{Nx}$ rats and on histomorphometry, cardiac hypertrophy markers, kidney parameters, body weight, and organ weight for the study with $5 / 6 \mathrm{Nx}$ rats. Tukey's post-hoc test was employed whenever multiple comparisons were warranted. The analysis of aortic calcification employed a Kruskal-Wallis test followed by a Wilcoxon's exact test for each pairwise comparison.

For the primary $5 / 6 \mathrm{Nx}$ rat study, each of the other parameters was evaluated using repeated measures analysis of covariance (ANCOVA) with the baseline value as the covariate. Each parameter except vitamin D was then analyzed using an ANCOVA at each assessment due to significant treatment by day interaction. Vitamin D was analyzed using repeatedmeasures ANCOVA without the interaction effect in the model. Each $5 / 6 \mathrm{Nx}$ plus Ab group was compared with the $5 / 6 \mathrm{Nx}$ plus control group using Dunnett's post-hoc test. 


\section{Study approval}

All procedures were reviewed and approved by both Charles Rivers Laboratories and Amgen Institutional Animal Care and Use of Laboratory Animals committees.

\section{Acknowledgments}

The authors thank Jon Nilsen (Amgen Inc.) for review and editing and scientists at Charles River Laboratories, Stephen E. Wilson, Arlen Avakian, and Thomas Gruetzner, for expert technical and scientific assistance.

Received for publication October 11, 2011, and accepted in revised form May 10, 2012.

1. Liu S, Guo R, Simpson LG, Xiao ZS, Burnham CE, Quarles LD. Regulation of fibroblastic growth factor 23 expression but not degradation by PHEX. J Biol Chem. 2003;278(39):37419-37426.

2. Riminucci $M$, et al. FGF-23 in fibrous dysplasia of bone and its relationship to renal phosphate wasting. J Clin Invest. 2003;112(5):683-692.

3. Shimada T, et al. Targeted ablation of Fgf 23 demonstrates an essential physiological role of FGF23 in phosphate and vitamin D metabolism. J Clin Invest. 2004;113(4):561-568.

4. Consortium A. Autosomal dominant hypophosphataemic rickets is associated with mutations in FGF23. Nat Genet. 2000;26(3):345-348.

5. Shimada T, et al. Cloning and characterization of FGF23 as a causative factor of tumor-induced osteomalacia. Proc Natl Acad Sci U S A. 2001; 98(11):6500-6505.

6. Jonsson KB, et al. Fibroblast growth factor 23 in oncogenic osteomalacia and $\mathrm{X}$-linked hypophosphatemia. NEngl J Med. 2003;348(17):1656-1663.

7. Feng JQ et al. Loss of DMP1 causes rickets and osteomalacia and identifies a role for osteocytes in mineral metabolism. Nat Genet. 2006;38(11):1310-1315.

8. Benet-Pages A, Orlik P, Strom TM, LorenzDepiereux B. An FGF23 missense mutation causes familial tumoral calcinosis with hyperphosphatemia. Hum Mol Genet. 2005;14(3):385-390.

9. Topaz O, et al. Mutations in GALNT3, encoding a protein involved in O-linked glycosylation, cause familial tumoral calcinosis. Nat Genet. 2004; 36(6):579-581.

10. Urakawa I, et al. Klotho converts canonical FGF receptor into a specific receptor for FGF23. Nature. 2006;444(7120):770-774.

11. Shimada T, et al. FGF-23 is a potent regulator of vitamin D metabolism and phosphate homeostasis. J Bone Miner Res. 2004;19(3):429-435.

12. Ferrari SL, Bonjour JP, Rizzoli R. Fibroblast growth factor-23 relationship to dietary phosphate and renal phosphate handling in healthy young men. J Clin Endocrinol Metab. 2005;90(3):1519-1524.

13. Gutierrez O, et al. Fibroblast growth factor-23 mitigates hyperphosphatemia but accentuates calcitriol deficiency in chronic kidney disease. J Am Soc Nephrol. 2005;16(7):2205-2215.

14. Shigematsu T, et al. Possible involvement of circulating fibroblast growth factor 23 in the development of secondary hyperparathyroidism associated with renal insufficiency. Am J Kidney Dis. 2004; 44(2):250-256.

15. Go AS, Chertow GM, Fan D, McCulloch CE, Hsu $\mathrm{CY}$. Chronic kidney disease and the risks of death, cardiovascular events, and hospitalization. $N$ EnglJ Med. 2004;351(13):1296-1305.

16. London GM, Guerin AP, Marchais SJ, Metivier F, Pannier B, Adda H. Arterial media calcification in end-stage renal disease: impact on all-cause and car-
Address correspondence to: William G. Richards, Amgen Inc., One Amgen Center Drive MS 14-1-B, Thousand Oaks, California 91320, USA. Phone: 805.447.3106; Fax: 805.447.1982; E-mail: Brichard@amgen.com.

Nessa Hawkins's present address is: Neurozon LLC, Ventura, California, USA.

Russell C. Cattley's present address is: Auburn University, College of Veterinary Medicine, Auburn, Alabama, USA.

Xuechun Xia's present address is: Bio-X Institutes, Shanghai Jiao Tong University, Shanghai, China. diovascular mortality. Nephrol Dial Transplant. 2003; 18(9):1731-1740

17. Nitta K, et al. Left ventricular hypertrophy is associated with arterial stiffness and vascular calcification in hemodialysis patients. Hypertens Res. 2004; 27(1):47-52.

18. Raggi $\mathrm{P}$, et al. Cardiac calcification in adult hemodialysis patients. A link between end-stage renal disease and cardiovascular disease? J Am Coll Cardiol. 2002;39(4):695-701.

19. Chertow GM, Raggi P, Chasan-Taber S, Bommer J, Holzer H, Burke SK. Determinants of progressive vascular calcification in haemodialysis patients. Nephrol Dial Transplant. 2004;19(6):1489-1496.

20. Block GA, Hulbert-Shearon TE, Levin NW, Port FK. Association of serum phosphorus and calcium $\mathrm{x}$ phosphate product with mortality risk in chronic hemodialysis patients: a national study. Am J Kidney Dis. 1998;31(4):607-617.

21. Sambrook PN, et al. Serum parathyroid hormone is associated with increased mortality independent of 25-hydroxy vitamin d status, bone mass, and renal function in the frail and very old: a cohort study. J Clin Endocrinol Metab. 2004;89(11):5477-5481.

22. Fliser D, et al. Fibroblast growth factor 23 (FGF23) predicts progression of chronic kidney disease: the Mild to Moderate Kidney Disease (MMKD) Study. J Am Soc Nephrol. 2007;18(9):2600-2608.

23. Gutierrez OM, et al. Fibroblast growth factor 23 and left ventricular hypertrophy in chronic kidney disease. Circulation. 2009;119(19):2545-2552.

24. Seiler S, Reichart B, Roth D, Seibert E, Fliser D, Heine GH. FGF-23 and future cardiovascular events in patients with chronic kidney disease before initiation of dialysis treatment. Nephrol Dial Transplant. 2010;25(12):3983-3989.

25. Gutierrez OM, et al. Fibroblast growth factor 23 and mortality among patients undergoing hemodialysis. N Engl J Med. 2008;359(6):584-592.

26. Jean $\mathrm{G}$, et al. High levels of serum fibroblast growth factor (FGF)-23 are associated with increased mortality in long haemodialysis patients. Nephrol Dial Transplant. 2009;24(9):2792-2796.

27. Faul C, et al. FGF23 induces left ventricular hypertrophy. J Clin Invest. 2011;121(11):4393-4408.

28. Yu X, et al. Analysis of the biochemical mechanisms for the endocrine actions of fibroblast growth factor-23. Endocrinology. 2005;146(11):4647-4656.

29. Parker TG, Packer SE, Schneider MD. Peptide growth factors can provoke "fetal" contractile protein gene expression in rat cardiac myocytes. JClin Invest. 1990;85(2):507-514.

30. Scheinowitz M, Kotlyar A, Zimand S, Ohad D, Leibovitz I, Bloom N, Goldberg I, Nass D, Engelberg $\mathrm{S}$, Savion N, et al. Basic fibroblast growth factor induces myocardial hypertrophy following acute infarction in rats. Exp Physiol. 1998;83(5):585-593.

31. Yamazaki Y, et al. Anti-FGF23 neutralizing antibodies show the physiological role and structural features of FGF23. J Bone Miner Res. 2008;23(9):1509-1518.

32. Saito H, et al. Circulating FGF-23 is regulated by 1alpha,25-dihydroxyvitamin D3 and phosphorus in vivo. J Biol Chem. 2005;280(4):2543-2549.

33. Ben-Dov IZ, et al. The parathyroid is a target organ for FGF23 in rats. JClin Invest. 2007;117(12):4003-4008.

34. US Renal Data System. 2007 Annual Data Report: Atlas Of End-stage Renal Disease In The United States: International Comparisons. Bethesda, Maryland, USA: NIH, National Institute of Diabetes and Digestive and Kidney Diseases; 2007:239-254.

35. Calvo MS, Park YK. Changing phosphorus content of the U.S. diet: potential for adverse effects on bone. J Nutr. 1996;126(4 suppl):1168S-1180S.

36. French SA, Harnack L, Jeffery RW. Fast food restaurant use among women in the Pound of Prevention study: dietary, behavioral and demographic correlates. Int J Obes Relat Metab Disord. 2000; 24(10):1353-1359.

37. Reutens AT, Atkins R. The epidemiology of diabetic kidney disease. In: Ekoé JM, Rewers M, Williams R, Zimmet P. The Epidemiology Of Diabetes Mellitus. 2nd ed. Chichester, United Kingdom: John Wiley; 2008:499-518.

38. Hasegawa H, et al. Direct evidence for a causative role of FGF23 in the abnormal renal phosphate handling and vitamin $\mathrm{D}$ metabolism in rats with early-stage chronic kidney disease. Kidney Int. 2010; 78(10):975-980.

39. Bai X, Miao D, Li J, Goltzman D, Karaplis AC. Transgenic mice overexpressing human fibroblast growth factor 23 (R176Q) delineate a putativerole for parathyroid hormone in renal phosphate wasting disorders. Endocrinology. 2004;145(11):5269-5279.

40. Kempson SA, Lotscher M, Kaissling B, Biber J, Murer H, Levi M. Parathyroid hormone action on phosphate transporter mRNA and protein in rat renal proximal tubules. Am J Physiol. 1995;268(4 pt 2):F784-F791.

41. Murer H, Lotscher M, Kaissling B, Levi M, Kempson SA, Biber J. Renal brush border membrane $\mathrm{Na} / \mathrm{Pi}$-cotransport: molecular aspects in PTHdependent and dietary regulation. Kidney Int. 1996; 49(6):1769-1773.

42. Henley C, et al. The calcimimetic AMG 641 abrogates parathyroid hyperplasia, bone and vascular calcification abnormalities in uremic rats. Eur J Pharmacol. 2009;616(1-3):306-313.

43. Rodriguez M, Martinez-Moreno JM, RodriguezOrtiz ME, Munoz-Castaneda JR, Almaden Y. Vitamin D and vascular calcification in chronic kidney disease. Kidney Blood Press Res. 2011;34(4):261-268.

44. Moe SM. Vascular calcification and renal osteodystrophy relationship in chronic kidney disease. EurJ Clin Invest. 2006;36(Suppl 2):51-62.

45. Jablonski G, et al. Surgically induced uremia in rats. I: Effect on bone strength and metabolism. Biosci Rep. 1993;13(5):275-287. 